\title{
Locally enhanced electric field treatment (LEEFT) for water disinfection
}

\author{
Jianfeng Zhou, Ting Wang, Cecilia Yu, Xing Xie (ه) \\ School of Civil and Environmental Engineering, Georgia Institute of Technology, Atlanta, GA 30332, USA
}

\section{H I G H L I G H T S}

- Nanowire-assisted LEEFT is applied for water disinfection with low voltages.

- LEEFT inactivates bacteria by disrupting cell membrane through electroporation.

- Multiple electrodes and device configurations have been developed for LEEFT.

- The LEEFT is low-cost, highly efficient, and produces no DBPs.

- The LEEFT can potentially be applicable for water disinfection at all scales.

\section{A R T I C L E I N F O}

\section{Article history:}

Received 30 December 2019

Revised 7 February 2020

Accepted 20 February 2020

Available online 16 May 2020

\section{Keywords:}

Water treatment

Nanotechnology

Pathogen inactivation

Electroporation

Nanowire

Chemical-free

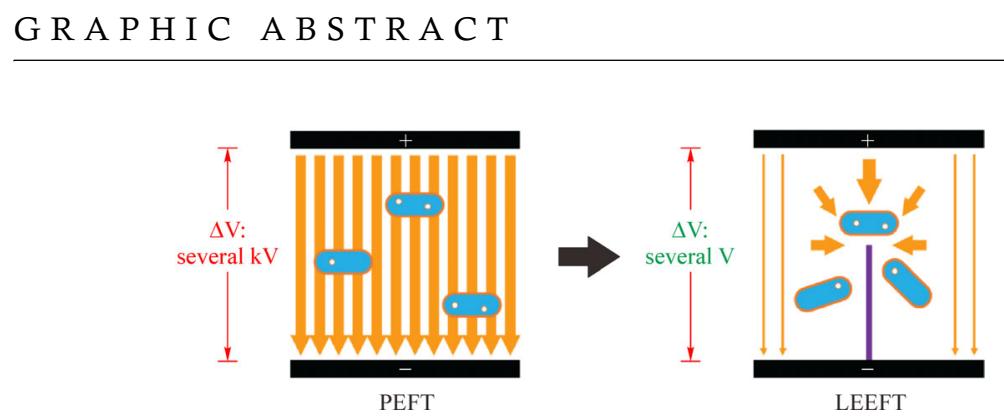

A B S T R A C T

Water disinfection is a critical step in water and wastewater treatment. The most widely used chlorination suffers from the formation of carcinogenic disinfection by-products (DBPs) while alternative methods (e.g., UV, $\mathrm{O}_{3}$, and membrane filtration) are limited by microbial regrowth, no residual disinfectant, and high operation cost. Here, a nanowire-enabled disinfection method, locally enhanced electric field treatment (LEEFT), is introduced with advantages of no chemical addition, no DBP formation, low energy consumption, and efficient microbial inactivation. Attributed to the lightning rod effect, the electric field near the tip area of the nanowires on the electrode is significantly enhanced to inactivate microbes, even though a small external voltage (usually $<5 \mathrm{~V}$ ) is applied. In this review, after emphasizing the significance of water disinfection, the theory of the LEEFT is explained. Subsequently, the recent development of the LEEFT technology on electrode materials and device configurations are summarized. The disinfection performance is analyzed, with respect to the operating parameters, universality against different microorganisms, electrode durability, and energy consumption. The studies on the inactivation mechanisms during the LEEFT are also reviewed. Lastly, the challenges and future research of LEEFT disinfection are discussed.

C The Author(s) 2020. This article is published with open access at link.springer.com and journal.hep. com.cn

\section{Introduction}

The practice of chlorine disinfection has greatly impacted the human drinking water experience ever since its implementation in the 1900s. Although waterborne diseases such as typhoid fever, cholera, and dysentery

$\triangle$ Corresponding author

E-mail: xing.xie@ce.gatech.edu

Special Issue-Accounts of Aquatic Chemistry and Technology Research (Responsible Editors: Jinyong Liu, Haoran Wei \& Yin Wang) remain the leading causes of debilitating illness or even death in populations without adequate sanitation, much of their threat to human health has been obviated in welldeveloped countries (CDC, 1999). This is due to these countries' widespread use of disinfectants and disinfection technologies within their public health facilities, the foremost of these methods being chlorination for its cheap cost, high efficiency, and reliable performance (Morris et al., 1992).

Despite its many advantages, chlorination also poses a unique problem for the $21^{\text {st }}$ century: the persistent presence of disinfection by-products (DBPs) in treated waters 
(Sedlak and von Gunten, 2011). Dissolved free chlorine is toxic to microbial life because it disrupts cell homeostasis via damaging the cell membrane or genetic information held within; however, its high reactivity also causes it to combine with naturally occurring and synthetic organic matter to form DBPs (Westerhoff et al., 2005). These include known human carcinogens such as chloroform and the other trihalomethanes, but also many lesser-known and emerging DBPs that occur in trace amounts (Deborde and Von Gunten, 2008). As industrialization progresses and the raw water matrix grows ever more complex, the sheer number of chemical byproducts formed in our treated waters is quickly outstripping our ability to keep up with them, and their apparent increasing genotoxicity has also been cause for concern (Plewa et al., 2004).

The microbial standards of our drinking water cannot be compromised; therefore, the challenge in resolving this chemical concern lies in maintaining the same degree of sanitation whilst decreasing the amount of DBPs being formed. Developed in the 2010s, locally enhanced electric field treatment (LEEFT) has been emerging as a promising alternative disinfection technique. The LEEFT is a physical treatment process that aims to utilize a strong electric field to disrupt cell membranes and thus inactivate pathogens. The electrodes installed in a LEEFT device are typically modified with one-dimensional nanostructures, such that the electric field is greatly enhanced locally near the tips of the nanostructures. This review serves as the introduction to the LEEFT technology with topics covering the basics theory, electrode development, configuration design, disinfection performance, inactivation mechanisms, and remaining challenges.

\section{Theory of electroporation and the LEEFT}

When microbial cells (e.g., bacteria and protozoa) are exposed to an external electric field, the lipid bilayer membrane of the cells could be considered as a capacitor. Charged ions on the inside and outside of the cell move under electrophoretic force and redistribute on the two sides of the lipid bilayer, generating a transmembrane potential $\Delta V_{i}$ (Kotnik et al., 1997),

$$
\begin{gathered}
\Delta V_{i}=f_{\mathrm{s}} R E_{e x t} \cos \theta\left[1-\exp \left(-\frac{t}{\tau}\right)\right], \\
\tau=\frac{R C_{m}}{\left(\frac{2 \lambda_{e} \lambda_{i}}{2 \lambda_{e}+\lambda_{i}}\right)+\frac{R}{d} \lambda_{m}},
\end{gathered}
$$

where $f_{s}$ is a function relating to the electric and geometric properties of the cell and the medium; $R$ is the radius of the cell; $E_{\text {ext }}$ is external electric field intensity; $\theta$ is the angle between a tangent at the studied point on the surface of cell and the direction of the electric field; $t$ is the duration of the external electric field; and $\tau$ is the membrane charging constant, which is related to the surface capacitance of the membrane $\left(C_{m}\right)$, the membrane thickness $(d)$, and the conductivity of intracellular cytoplasm $\left(\lambda_{i}\right)$, extracellular medium $\left(\lambda_{e}\right)$, and membrane $\left(\lambda_{m}\right)$. After the transmembrane potential is built up, water molecules initially confined at the membrane-water interface tend to orient their dipoles along the local electric field created by the transmembrane potential, forming a water column spanning across the lipid bilayer. This leads to a reorientation of the lipids with their hydrophilic headgroups towards the water column, which initiates the generation of pores on the membrane, or electroporation (Kotnik et al., 2019) (Fig. 1(a)).

Under a relatively low transmembrane potential, the pores formed on the membrane are transient, meaning they could reseal after the electric field is removed. This is termed as reversible electroporation, which provides temporary pathways for cross-membrane transport but also maintains high cell viability (Kotnik et al., 2015). Reversible electroporation has been widely used for the intracellular delivery of various molecules (e.g., drug, nucleic acids, or proteins) (Stewart et al., 2018). A sufficiently high transmembrane potential (typically about $1 \mathrm{~V}$ ) leads to permanent pores and irreversible electroporation, thus causing cell inactivation (Pethig and Markx, 1997). Irreversible electroporation has also been studied for a wide range of applications, including clinical therapy (Jiang et al., 2015), tissue ablation (Edd et al., 2006), food processing and sterilization (Barba et al., 2015), and hospital water disinfection (Gusbeth et al., 2009).

The process of cell inactivation by irreversible electroporation is developed to become a technique called pulsed electric field treatment (PEFT), which is considered as a non-thermal physical process. For a typical PEFT, media containing pathogens is placed between two parallel plate electrodes and applied with strong electric pulses (Fig. 1(b)). During a PEFT, the specific electric field strength and exposure time required for irreversible electroporation varies significantly across different microorganisms. For a spherical bacterium with a radius of $1 \mu \mathrm{m}$, the electric field intensity and exposure time required to achieve irreversible electroporation are about $10 \mathrm{kV} / \mathrm{cm}$ and a few microseconds, respectively (Shahini and Yeow, 2013; Wang et al., 2019). Because the inactivation requires a strong electric field but short exposure time, high voltage electric pulses with durations less than 100 microseconds are commonly applied. To achieve this strong electric field $(>10 \mathrm{kV} / \mathrm{cm})$, the distance between the two electrodes and the applied voltage are typically set as $<1 \mathrm{~cm}$ and $>10 \mathrm{kV}$, respectively. PEFT has been applied to effectively inactivate bacteria (including bacterial spores), viruses, and protozoa (Mizuno et al., 1990; Haas 
(a)
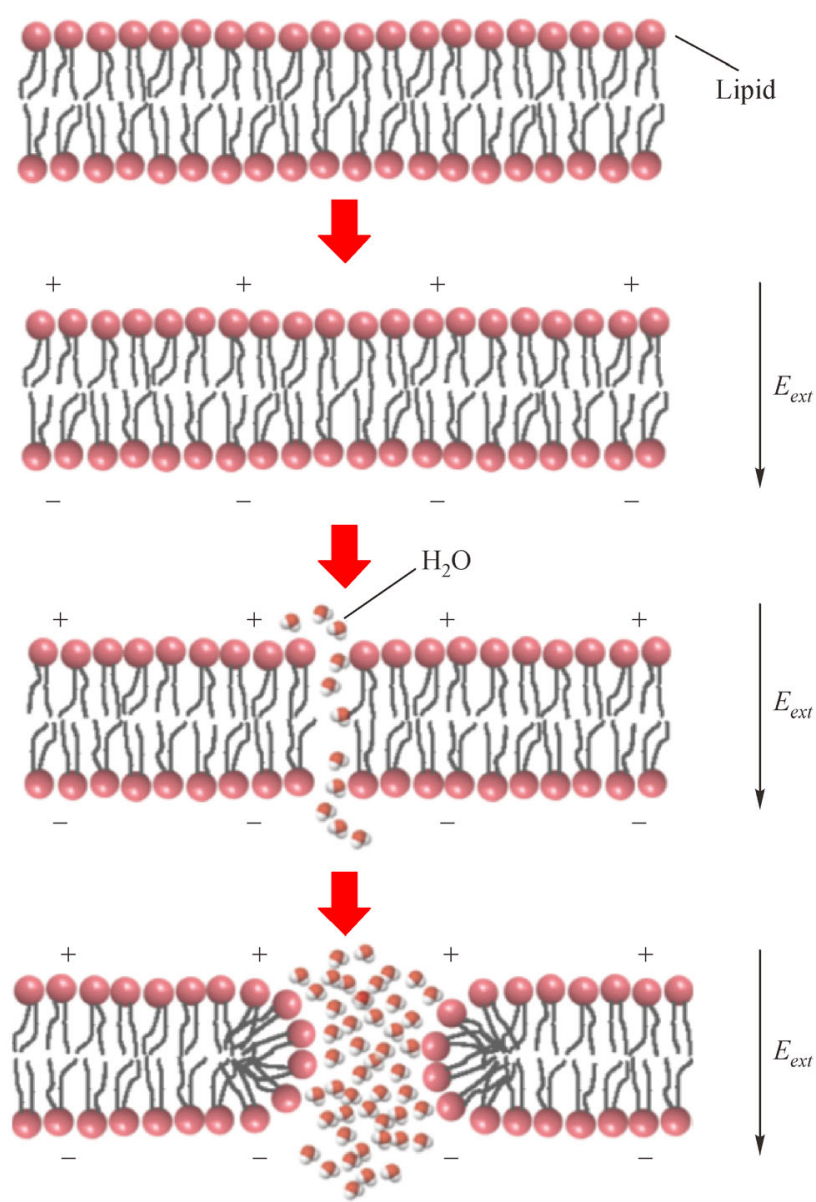

(b)
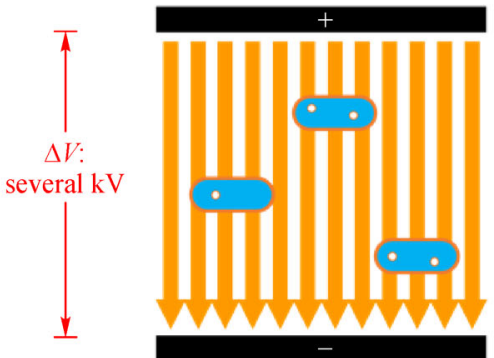

(c)

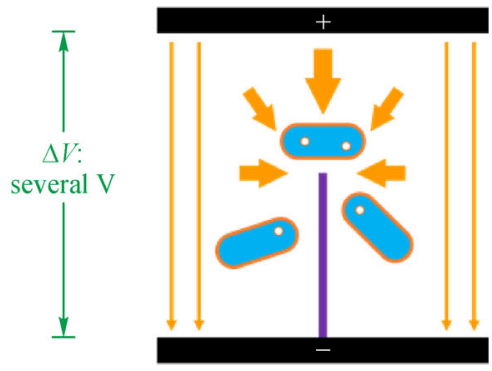

(d)

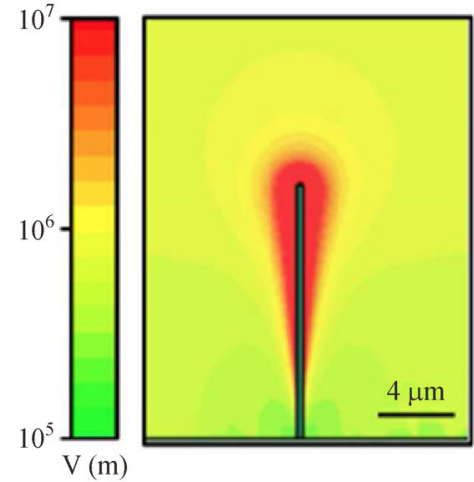

Fig. 1 Theory of the locally enhanced electric field treatment (LEEFT) for microbial inactivation. (a) Electroporation on the cell membrane under a strong external electric field, (b) Schematic of the pulsed electric field treatment, (c) Schematic of the LEEFT. The applied voltage is reduced from several $\mathrm{kV}$ to serval V, (d) Electric field distribution near the surface of CuONW (diameter, $100 \mathrm{~nm}$; length, $15 \mu \mathrm{m}$ ) in water showing the enhancement of the electric field strength (Liu et al., 2014).

and Aturaliye, 1999; Spilimbergo et al., 2003; Kotnik et al., 2015).

Compared to other inactivation methods (e.g., thermal, chlorine, and ultraviolet radiation), PEFT has the following advantages: i) it is very fast (6-log inactivation can be achieved within 100 microseconds) (Weaver and Chizmadzhev, 1996; Gusbeth et al., 2009; Shahini and Yeow, 2013); ii) no chemicals are added, and no DBPs are generated during treatment (Gusbeth et al., 2009; Kotnik et al., 2015); iii) it is effective for all bacteria, including "superbugs" that are resistant to multiple antimicrobials (Weaver and Chizmadzhev, 1996; Saulis, 2010; Kotnik et al., 2015); and iv) bacteria do not develop resistance (Gusbeth et al., 2009). The PEFT is also distinct from electrochemical processes where inactivation is due to in-situ generated microbicidal chemicals (e.g., reactive oxygen and chlorine species) and/or direction electrochemical oxidation (Vecitis et al., 2011; Cho et al., 2014).
Nevertheless, PEFT has not been widely implemented for liquid-food processing so far, and no practical application for water disinfection is reported. Major obstacles include high energy consumption of the short but intensive electric pulses (typically $10-100 \mathrm{~kJ} / \mathrm{L}$ ), the extra cost that may be required to prevent overheating, and technical limitations to achieve a high-strength electric field without the risk of arcing at a large scale (Saldaña et al., 2014; Kotnik et al., 2015).

To overcome the limitations of PEFT, an alternative is LEEFT (Fig. 1(c)). Attributed to the lightning rod effect, which occurs when a metallic rod is placed into a uniform electric field, the electric field strength near the tip area of the rod will be enhanced. By modifying the electrodes with tip structures that have high aspect ratios(length to diameter ratio), e.g., carbon nanotubes (CNTs) and nanowires, the electric field can be enhanced locally (i.e., near the tip) by several orders of magnitude (Rojas- 
Chapana et al., 2004; Shahini and Yeow, 2013; Poudineh et al., 2014). This local electric field enhancement effect has also been analyzed computationally using a finite element method. As the simulation generated by COMSOL Multiphysics shows, the electric field reaches the maximum value (higher than $100 \mathrm{kV} / \mathrm{cm}$ ) on the surface of the nanowire tips, and decreases with increasing distance away from the nanowires (Liu et al., 2014; Huo et al., 2017) (Fig. 1(d)). As a result, cell inactivation can be achieved by LEEFT operating at a significantly lower voltage.

\section{$3 \quad$ LEEFT electrodes and devices}

Based on the theory explained above, researchers have reported a series of low-voltage-powered LEEFT devices, and the electrodes are the core component of these devices. The strategy applied to fabricate LEEFT electrodes is modifying conductive substrates (e.g., carbon or copper) with high-aspect-ratio nanowires. The nanowires are typically about 5-10 $\mu \mathrm{m}$ long and less than $100 \mathrm{~nm}$ thick at the tips.

In the first demonstrations of the LEEFT, the electrodes were made by modifying three-dimensional CNT composite electrodes with silver nanowires (Figs. 2(a)-2(c)) (Schoen et al., 2010; Liu et al., 2013). Soon after that, copper-oxide nanowire modified $\mathrm{Cu}$ electrodes (CuONW$\mathrm{Cu}$ ) were prepared by simply heating copper in the air to lower the cost and increase the scalability (Figs. 2(d)-2(f)) (Liu et al., 2014; Huo et al., 2016). Later on, copperphosphide nanowire modified $\mathrm{Cu}$ electrodes $\left(\mathrm{Cu}_{3} \mathrm{PNW}\right.$ $\mathrm{Cu}$ ) were fabricated through electrochemical anodization plus chemical vapor deposition, considering that $\mathrm{Cu}_{3} \mathrm{P}$ is more stable than $\mathrm{CuO}$ in water (Figs. 2(g)-2(i)) (Huo et al., 2018). Recently, to enhance the durability of the electrodes, a poly-dopamine (PDA) protective coating was applied to both $\mathrm{CuONW}-\mathrm{Cu}$ (Figs. 2(j)-2(1)) and $\mathrm{Cu}_{3} \mathrm{PNW}-\mathrm{Cu}$ electrodes (Figs. 2(m)-2(o)) (Huo et al., 2019a; Huo et al., 2019b).

The desired nanowires for LEEFT disinfection should have the following features: i) The nanowires preferably stand vertically on the electrode surface with accessible tips rather than lying flat. ii) Nanowires with higher aspect ratios give a greater enhancement effect, which can reduce the necessary applied voltage. iii) They should not be too dense, otherwise the enhancement effect is diminished. iv) The nanowires should be made from conducting materials with sufficient stiffness and should be strongly attached to the electrode. v) The substrates and nanowires should not be toxic to humans and pose secondary contamination threat to the treated water.

Most of the early developed LEEFT devices consisted of two porous nanowire-modified electrodeshostedin parallel in a plastic chamber (Fig. 3(a)). The LEEFT electrodes were based on macroscale porous (e.g., mesh or foam) substrates with pore sizes larger than several hundred micrometers (Figs. 2(b), 2(e), 2(h), 2(k), 2(n)). For the LEEFT, water flowed through the pores of the two electrodes (Figs. 3(b) and 3(c)). Notably, the pore size of the porous electrodes was far larger than normal microorganisms so that size screening is not a major mechanism of microbial removal. A dielectric septum was usually placed in between the two electrodes to prevent shortcircuiting.

The recently developed coaxial-electrode LEEFT device (a)
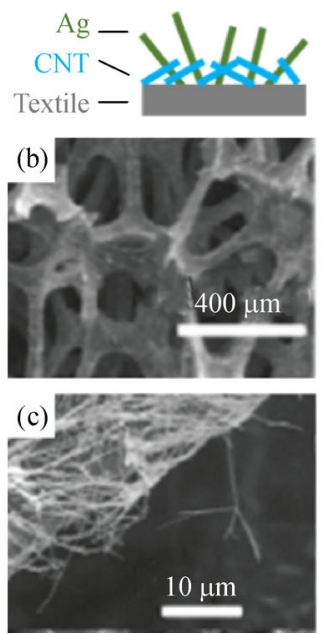

(d)
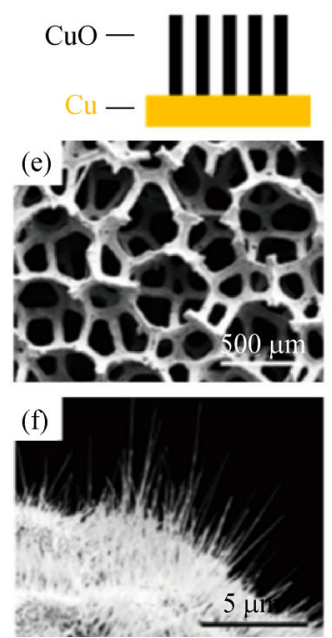

(g)
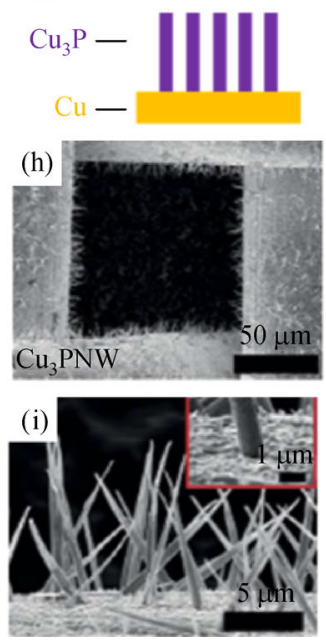

(j)
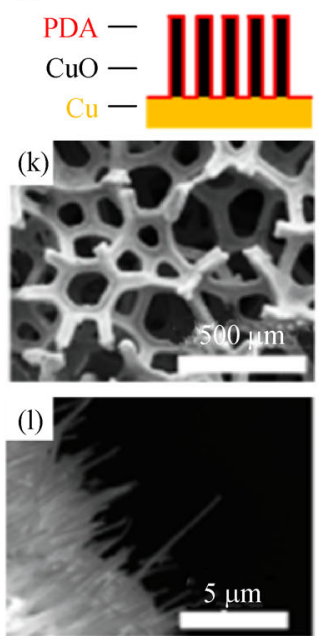

(m)
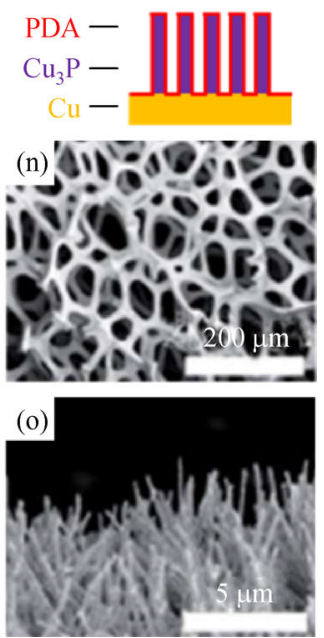

Fig. 2 Electrode materials for LEEFT disinfection. (a-c) AgNW modified CNT composite (Liu et al., 2013), (d-f) CuONW-Cu (Huo et al., 2016), (g-i) $\mathrm{Cu}_{3}$ PNW-Cu (Huo et al., 2018), (j-1) PDA-CuONW-Cu (Huo et al., 2019b), (m-o) PDA-Cu 3 PNW-Cu (Huo et al., 2019a). The first line (a, d, g, j, \& m) shows the schematic, second line (b, e, h, k, \& n) the macrostructures, and third line (c, f, i, l, \& o) the nanowires of the electrodes. 
(a)

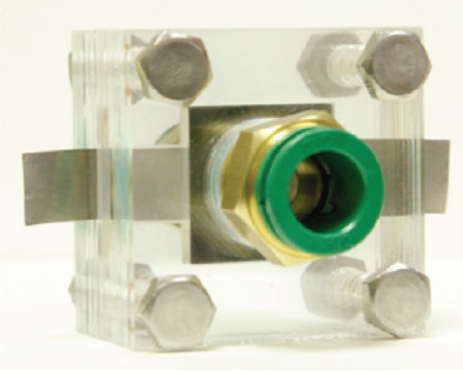

(b)

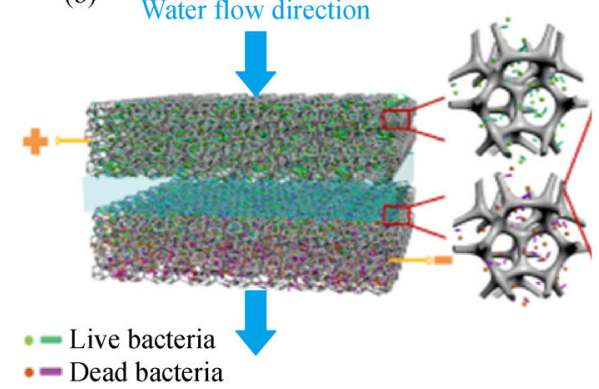

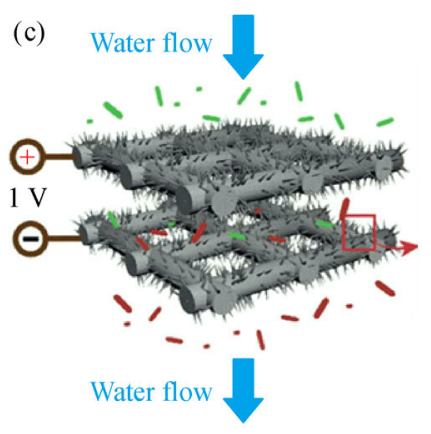

(e)

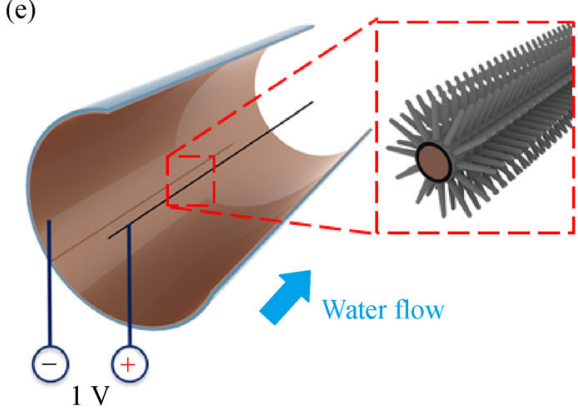

(f)
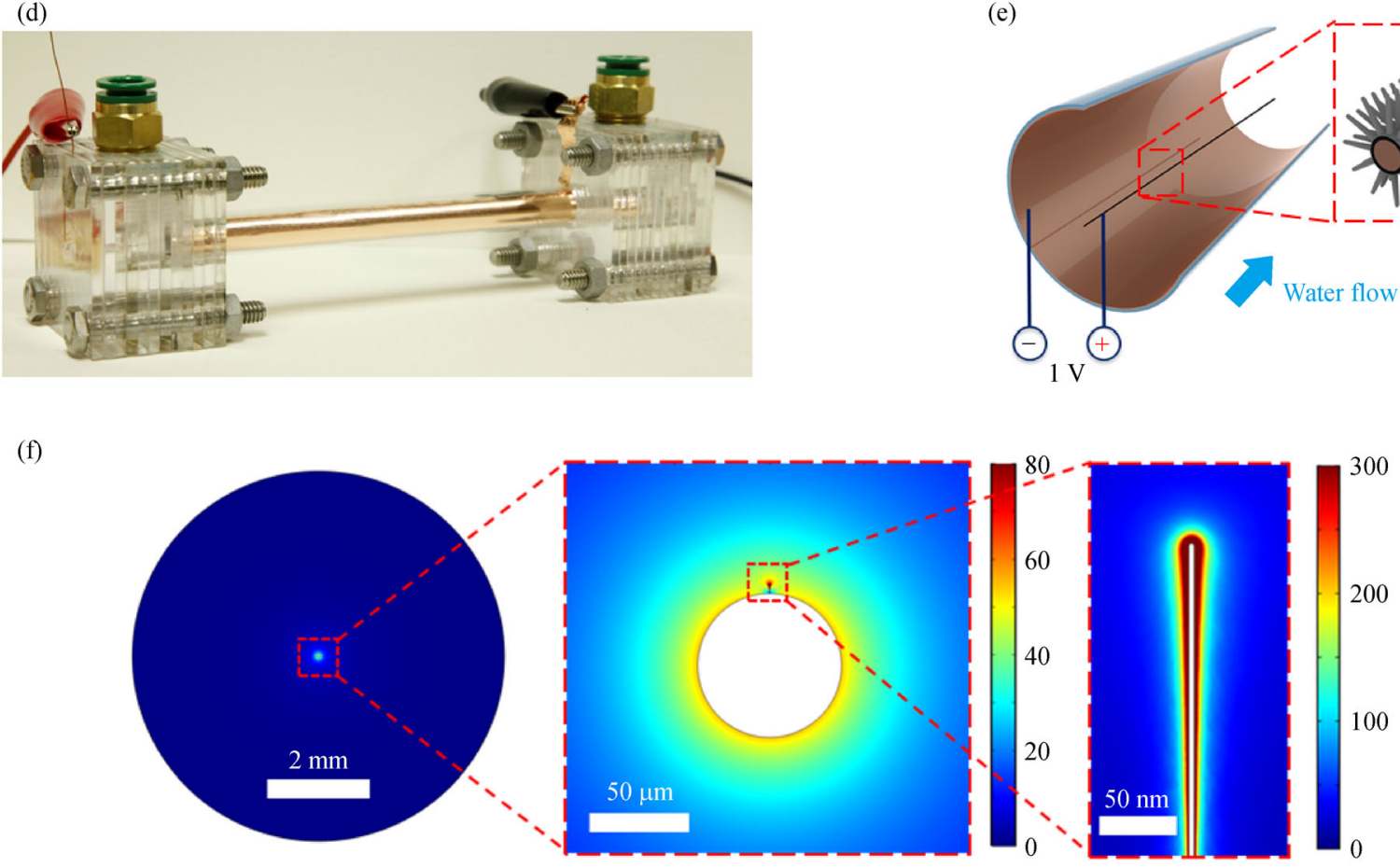

Fig. 3 LEEFT devices. (a) The image of a flow-through LEEFT device with two porous electrodes, (b, c) Schematics show the porous electrodes ((b) for foam and (c) for mesh) modified with nanowires (Liu et al., 2013, Huo et al., 2018), (d, e) The image and schematic of a coaxial-electrode LEEFT device, respectively (Zhou et al., 2019a, Zhou et al., 2019b), (f) Electric field simulation on the cross-section of the coaxial-electrode device showing the non-uniform distribution of the electric field with a two-level strength enhancement (Zhou et al., 2019b).

was made of an outer electrode and a center electrode (Fig. 3(d)) (Zhou et al., 2019b). The outer electrode was a cylindrical metal sheet while the center electrode was a coaxial thin wire modified with nanowires (Fig. 3(e)). The electric field strength between the coaxial electrodes was defined by Equation 3:

$$
E_{\mathrm{s}}=\frac{U}{s \cdot \ln \frac{r_{c}}{r_{o}}},
$$

where $E_{\mathrm{s}}$ was the electric field strength at the location with a distance of $\mathrm{s}$ from the center electrode, $U$ was the external applied voltage, and $r_{c}$ and $r_{o}$ were the radius of the center and outer electrodes, respectively. Thus, when approaching near to the center electrode $(s)$, the electric field strength was higher. The maximum electric field strength of the asmade coaxial-electrode device $\left(r_{c}=76 \mu \mathrm{m}\right.$ and $r_{o}=0.95$ $\mathrm{cm}$ ) was 26 times higher than that of the conventional parallel-plate configuration. Meanwhile, the implementation of the nanowire-modified center electrode enabled a second-level electric field enhancement (Fig. 3(f)). Negatively charged microbes were driven towards the center electrode (set to positive) attributed to both electrophoretic and dielectrophoretic forces. Due to its tubular configuration, the coaxial-electrode LEEFT device can be directly adopted to water pipelines. With future development and scaling up, the coaxial-electrode LEEFT device can potentially serve as an alternative of residual chlorine for 
secondary disinfection, which is to maintain the antimicrobial effect during water transport and delivery.

\section{Performance of the LEEFT for water disinfection}

The disinfection performance of the LEEFT was measured by a standard microbial plating technique and quantified by $\log$ inactivation efficiency (Fig. 4(a)). The inactivation was mainly influenced by two key parameters, the treatment capacity and the specific energy consumption. The treatment capacity was represented by the flux $(J, J=Q /$ $A$, where $Q$ was the flow rate and $A$ was the electrode surface area) in the parallel-plate LEEFT system because once the bacteria flowed through the electrodes, the inactivation stopped. This process was similar to the membrane filtration technology. On the other hand, the hydraulic retention time was used to represent treatment capacity in the coaxial-electrode system, as it was (a)
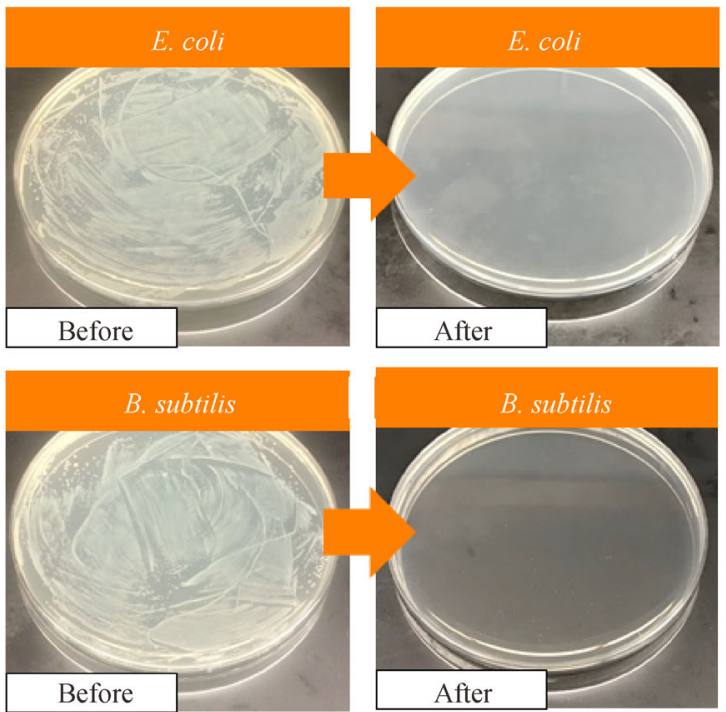

(c)

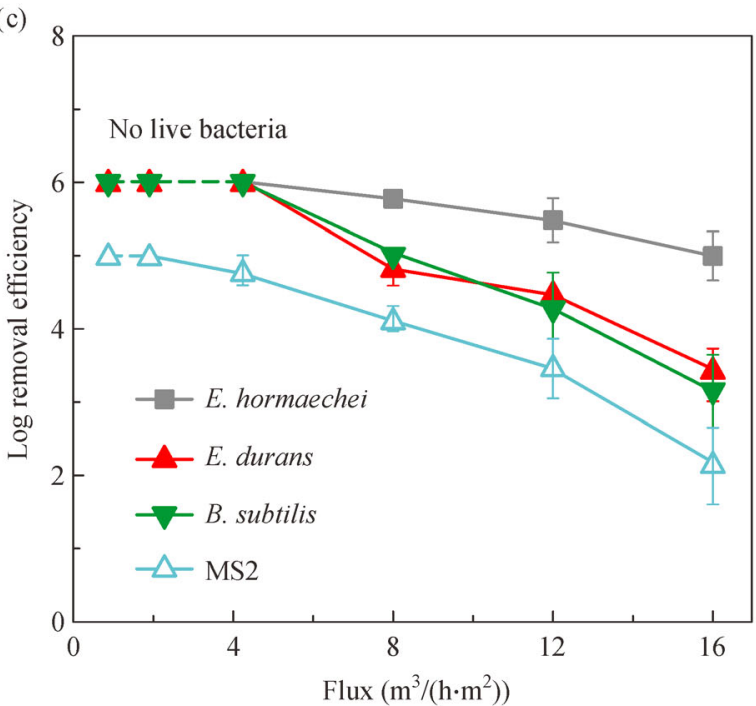

(b)

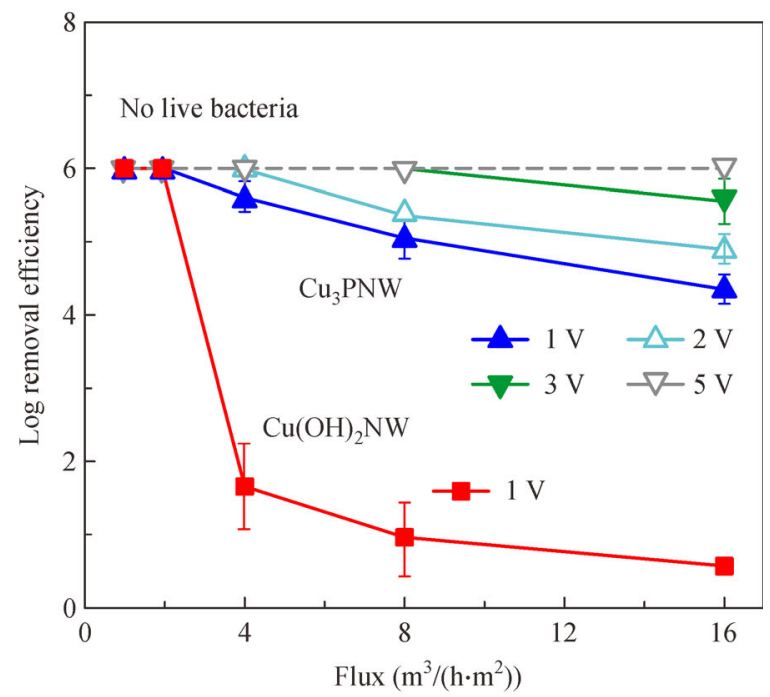

(d)

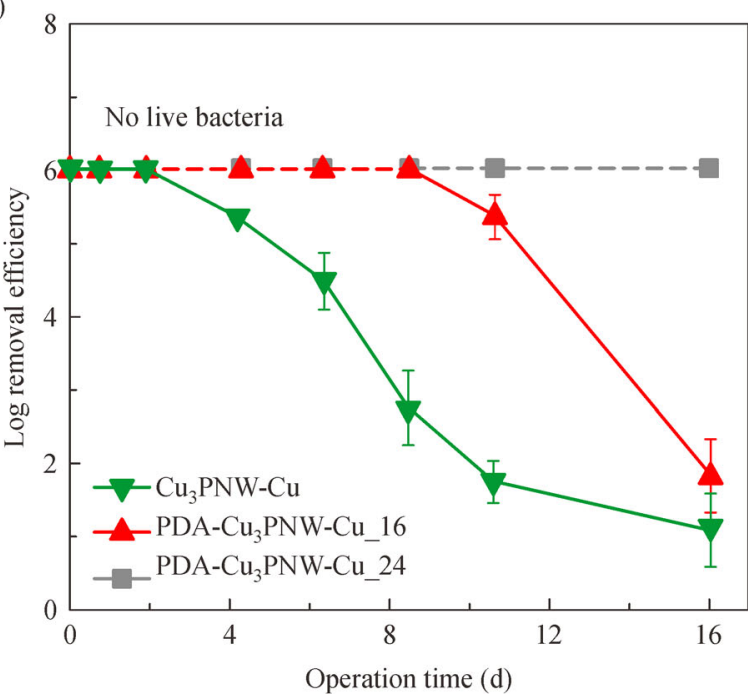

Fig. 4 Disinfection performance of the LEEFT. (a) Quantitative measurement of model bacteria (E. coli and Bacillus subtilis as gram negative and positive bacteria examples, respectively) before and after the LEEFT by a standard microbial plating technique (Ding et al., 2019), (b) $E$. coli inactivation efficiency with $\mathrm{Cu}_{3} \mathrm{PNW}-\mathrm{Cu}$ and $\mathrm{Cu}(\mathrm{OH})_{2}-\mathrm{Cu}$ electrodes with different voltages $(1,2,3$, and $5 \mathrm{~V})$ and different fluxes (from 1 to $16 \mathrm{~m}^{3} /\left(\mathrm{h} \cdot \mathrm{m}^{2}\right)$ ). $\mathrm{Cu}(\mathrm{OH})_{2}-\mathrm{Cu}$ is an intermediate product of the $\mathrm{Cu}_{3} \mathrm{P}-\mathrm{Cu}$ electrode (Huo et al., 2018), (c) Disinfection efficiency of E. hormaechei, E. durans, B. subtilis, and virus MS2 by PDA-Cu $\mathrm{Cu}_{3} \mathrm{PNW}-\mathrm{Cu}$ electrodes with AC (peak voltage of $1 \mathrm{~V}$; frequency of $10^{6} \mathrm{~Hz}$ ) (Huo et al., 2019a), (d) Long-term bacterial disinfection efficiency of the PDA-Cu $\mathrm{PNW}_{3} \mathrm{Cu}$ electrodes. The numbers after the electrodes (16 \& 24) stand for the PDA coating time (Huo et al., 2019a). 
considered as a plug flow reactor. The specific energy consumption was associated to the applied voltage. In general, there were two trade-offs, wherein one was between inactivation efficiency and treatment capacity and the other was between inactivation efficiency and energy consumption. The inactivation efficiency was higher with lower flux (or higher hydraulic retention time), since the microbial cells had more opportunity to get closer to the tips of the nanowires where the electric field is stronger (Fig. 4(b)). Higher applied voltage led to a higher electric field intensity, and thus a better inactivation result (Fig. 4 (b)). As the transmembrane potential needed to be built up across the bacterial cell membrane to initiate electroporation, a minimum voltage of $\sim 1 \mathrm{~V}$ was found to be necessary for effective microbial inactivation. For example, 6-log inactivation of $E$. coli was achieved in the parallelelectrode system with a flux of $2 \mathrm{~m} /\left(\mathrm{h} \cdot \mathrm{m}^{2}\right)$ and in the coaxial-electrode system with a hydraulic retention time of $10 \mathrm{~min}$.

Different species of bacteria were tested, including gram-positive $\left(\mathrm{G}^{+}\right)$and gram-negative $\left(\mathrm{G}^{-}\right)$species, to examine the universal inactivation performance of the LEEFT. Previous studies showed that gram-positive bacteria were slightly more resistant against LEEFT disinfection, but the difference was not significant (Fig. 4 (c)). A 6-log inactivation could be achieved against 7 species of bacteria $\left(\mathrm{G}^{-}:\right.$E. coli, Salmonella enterica, and Enterobacter hormaechei; $\mathrm{G}^{+}$: Enterococcus faecalis, Bacillus subtilis, Enterococcus durans, and Staphylococcus epidermidis) with a voltage as low as $1 \mathrm{~V}$ (Fig. 4(c)) (Liu et al., 2013; Huo et al., 2019b; Zhou et al., 2019a). In addition, the LEEFT could also effectively inactivate MS2, a model virus often used as a surrogate for human enteric viruses. For example, the PDA- $\mathrm{Cu}_{3} \mathrm{PNW}-\mathrm{Cu}$ electrodes achieved >5-log inactivation of MS2 with a $1 \mathrm{~V} \mathrm{AC}$ voltage applied (Fig. 4(c)). Samples with different water matrices were also tested, and the LEEFT disinfection was observed effective ( $>6$-log inactivation of $E$. coli) in DI water, saline solution, tap water, lake water, and secondary wastewater effluent (Huo et al., 2016; Huo et al., 2019b; Zhou et al., 2019a).

The durability, i.e., how long the electrodes can be used to effectively inactivate microbes, is also a key parameter to characterize for the LEEFT, and it is affected by both chemical and mechanical stresses. As metal, metal oxides, or metal phosphide have been used for the LEEFT electrodes, metal ions can dissolve from the electrode under certain electrochemical conditions, resulting in corrosion-like damage to the nanowires. The mechanical stress is mainly due to the sheer force of the water flow, which breaks the nanowires physically. Thus, the effluent copper concentration is an important parameter for examining the loss of nanowires. When $\mathrm{CuONW}-\mathrm{Cu}$ electrodes were used for LEEFT disinfection $(1 \mathrm{~V} \mathrm{DC}$, $1.8 \mathrm{~m}^{3} /\left(\mathrm{h} \cdot \mathrm{m}^{2}\right)$ flux $), \mathrm{Cu}$ concentration reached $\sim 500 \mu \mathrm{g} / \mathrm{L}$
(Huo et al., 2019b). Although this concentration is still lower than the USEPA's maximum contaminant level goal of $1.3 \mathrm{mg} / \mathrm{L}$ (USEPA, 2009) for drinking water, it indicates severe electrode decay. The lifespan of the $\mathrm{CuONW}-\mathrm{Cu}$ electrode was less than $10 \mathrm{~min}$. The metal release was greatly controlled with the development of more durable electrodes. The effluent $\mathrm{Cu}$ concentration of the LEEFT with PDA- $\mathrm{Cu}_{3} \mathrm{PNW}-\mathrm{Cu}$ electrodes was reduced to less than $4 \mu \mathrm{g} / \mathrm{L}\left(1 \mathrm{VAC}, 10^{6} \mathrm{~Hz}\right.$ frequency, $4 \mathrm{~m}^{3} /\left(\mathrm{h} \cdot \mathrm{m}^{2}\right)$ flux, $>6$ - log inactivation of $E$. coli), a concentration that should not be of any concern to human health and the ecosystem (Flemming and Trevors, 1989; Zhou et al., 2019b). Accordingly, the lifespan was extended to more than 15 days (Fig. 4(d)).

The LEEFT disinfection is an energy efficient process with a specific energy consumption $(E)$ of $1.2-100 \mathrm{~J} / \mathrm{L}$ (calculated from the experimental data using $E=(U \times I) / Q$, where $U, I, Q$ are the applied voltage, current, and flow rate, respectively) (Liu et al., 2013; Huo et al., 2018). For practical use, the LEEFT is also expected to consume much lower energy than conventional water disinfection methods (UV, 20-60 J/L; ozone, 50-100 J/L; membrane, 500-5000 $\mathrm{J} / \mathrm{L}$ ) that target on the bulk water (Chang et al., 2008). Specifically, the chlorine concentration in the bulk solution should achieve a certain level to enable an effective disinfection. The LEEFT, on the other hand, targets only on the microbes in water. The microbes would be sent to the regions near the electrode surface, exposed to the locally enhanced electric field, and inactivated. The bulk water is only exposed to the background electric field with a much lower strength, resulting in a low energy consumption for the overall LEEFT process.

\section{Inactivation mechanism study}

The LEEFT has demonstrated superior performance for microbial inactivation. The absence of nanowires led to a dramatic decrease of the inactivation efficiency. For example, when the electrode substrate was modified with nanoparticles, the inactivation efficiency dropped by $\sim 3$ logs (Fig. 5(a)). In the coaxial-electrode system, compared with the 6-log inactivation using the PDA-coated $\mathrm{CuONW}-\mathrm{Cu}$ electrodes, a PDA-coated $\mathrm{Cu}$ electrode demonstrated almost no inactivation with $1 \mathrm{~V}$ applied voltage (Fig. 5(b)). Nevertheless, the mechanisms for microbial inactivation are still not fully understood. Irreversible electroporation induced by the nanowireenhanced electric field is believed to be the main mechanism. Two methods were tried to observe the irreversible electroporation after the LEEFT. Propidium iodide (PI) is a florescent dye that can penetrate damaged cell membranes and distinguish dead cells from live ones. Most of the treated microbes were stained by PI, which indicated the disruption of the cell membrane (Figs. 5(c) 
(a)

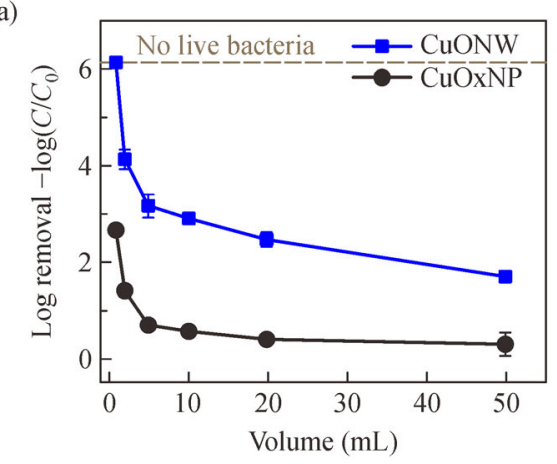

(c)

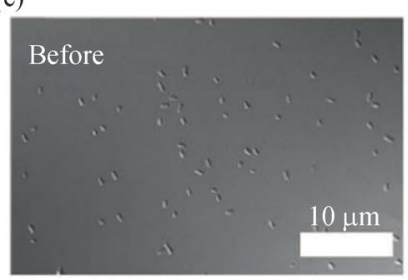

(f)

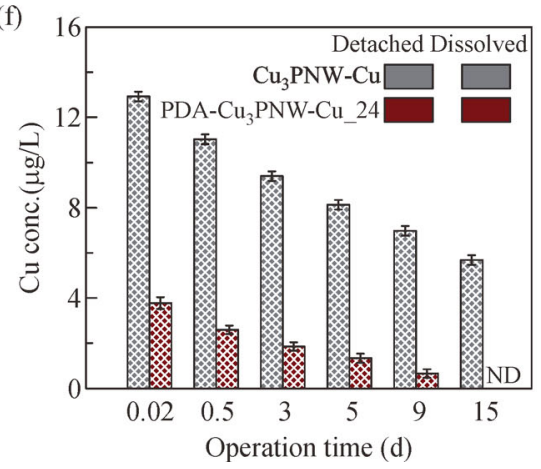

(b)

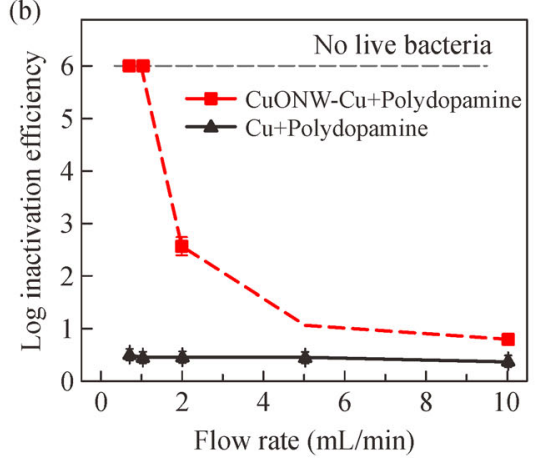

(e)

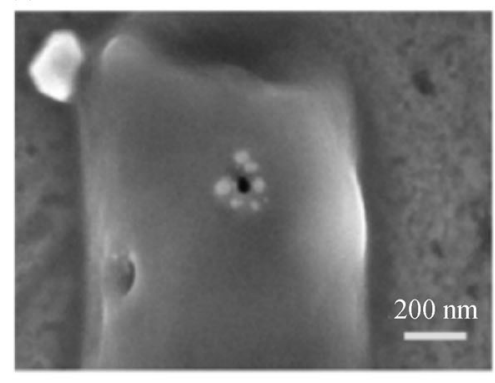

(d)

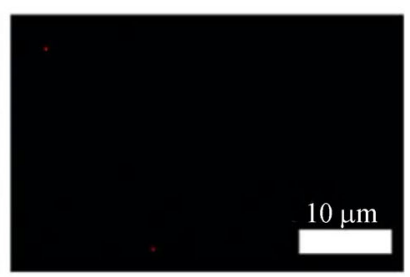

(g)

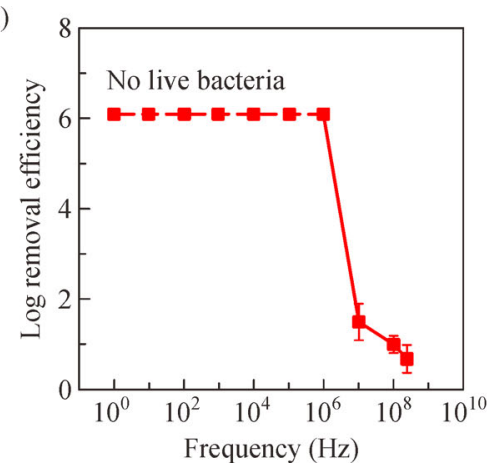

(h)

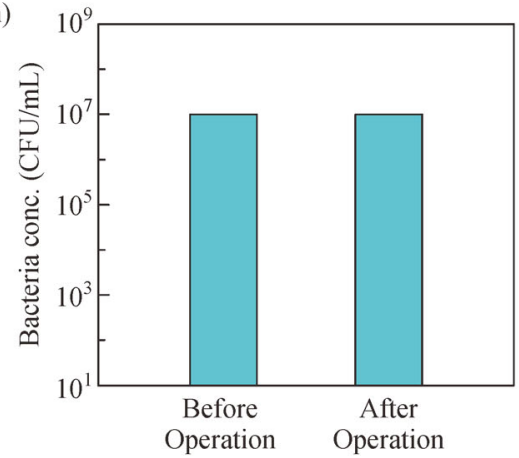

Fig. 5 Disinfection mechanisms of the LEEFT. (a) Inactivation efficiency of $E$. coliusing $\mathrm{CuONW}-\mathrm{Cu}$ and $\mathrm{Cu}_{\mathrm{x}} \mathrm{ONP}-\mathrm{Cu}$ showing enhanced performance by 1D nanowire structure (Liu et al., 2014), (b) Inactivation efficiency of $E$. coli using a PDA-coated copper wire as the center electrode under $1 \mathrm{~V}$ applied voltage (Zhou et al., 2019a), (c, d) Bright-field and fluorescence microscopy images of $E$. coli samples before (c) and after (d) LEEFT ( $\mathrm{Cu}_{3} \mathrm{P}-\mathrm{Cu}$ electrodes) with a fixed voltage $(1 \mathrm{~V})$ and a fixed flux $\left(2 \mathrm{~m}^{3} /\left(\mathrm{h} \cdot \mathrm{m}^{2}\right)\right)(\mathrm{Huo} \mathrm{et}$ al., 2018$)$, (e) High-magnification SEM showing more than one pore formed on E. coli surface after LEEFT (AgNW-CNT composite, 20 V) (Liu et al., 2013), (f) $\mathrm{Cu}$ release of the $\mathrm{Cu}_{3}$ PNW-Cu and PDA-Cu 3 PNW-Cu electrodes during the long-term LEEFT (15 days; AC: peak voltage of $1 \mathrm{~V}$, and frequency of $10^{6} \mathrm{~Hz}$; flux: $4 \mathrm{~m}^{3} /\left(\mathrm{hm}^{2}\right)$ ). ND (not detectable) indicates that the $\mathrm{Cu}$ concentration in the effluent is lower than the detection limit $(0.1 \mathrm{mg} / \mathrm{L}$ ) (Huo et al., 2019a), (g) Inactivation efficiency for $E$. coli with an AC voltage of $1 \mathrm{~V}$ and different frequencies (from 1 to $3.5 \times 10^{8} \mathrm{~Hz}$ ) (Huo et al., 2018), (h) When the E. coli sample passed through the PDA-CuONW electrodes with a fixed flux (1.8 $\mathrm{m}^{3} /\left(\mathrm{h} \cdot \mathrm{m}^{2}\right)$ ) and without applied voltage, no bacteria were inactivated (Huo et al., 2019b).

and 5(d)). The damage to the cell membrane can also be directly observed by SEM. Small-sized pores in the range of 10-100 nm were observed on the surface of the treated bacteria (Fig. 5(e)).

Other potential inactivation mechanisms have been considered not significant players in the LEEFT disinfection. When DC or low-frequency AC voltages are applied to $\mathrm{Cu}$-based electrodes, it is inevitable to generate $\mathrm{Cu}$ ions, which are known to be antimicrobial. However, the $\mathrm{Cu}$ concentration of the LEEFT effluent has been reduced to less than $4 \mu \mathrm{g} / \mathrm{L}$ (Fig. 5(f)), a concentration far less than the effective level known to kill microbes. Treating $E$. coli with $100 \mu \mathrm{g} / \mathrm{L} \mathrm{Cu}$ for the same period of time only resulted in $<0.5 \mathrm{log}$ inactivation (Zhou et al., 2019b). When a highfrequency $\mathrm{AC}\left(>10^{4} \mathrm{~Hz}\right)$ voltage is used for the LEEFT disinfection, electrochemical reactions can be largely eliminated (Chang and Park, 2010). Nevertheless, high inactivation $(>6 \log )$ of $E$. coli still could be achieved even at a high frequency of $10^{6} \mathrm{~Hz}$ (Fig. $5(\mathrm{~g})$ ), indicating that electrochemical reactions do not contribute significantly (Huo et al., 2018).

Physical processes, such as adsorption of microbes in LEEFT devices and the mechanical stress induced by the nanowires upon direct contact, could also contribute to 
remove or inactivate microbes (Akhavan and Ghaderi, 2010). In addition, some of the reported LEEFT electrodes contain a thin layer of PDA, which has been applied for antimicrobial surface coating. However, control experiments excluded their significant contributions (Fig. 5(b)) (Huo et al., 2019b; Zhou et al., 2019a). In all LEEFT experiments, the optical density of the microbes in water did not change notably, meaning that the microbes went through the devices without being trapped inside (Huo et al., 2019b). When samples were flowed through LEEFT devices without external voltages, little inactivation was achieved (Fig. 5(h)), which suggested that direct contact alone, either with nanowires or PDA, was not enough for high inactivation and the electrical treatment is necessary (Zhou et al., 2019a). No change in the $\mathrm{pH}$ and temperature of the water was found during the LEEFT (Huo et al., 2016).

\section{Challenges and perspective}

Even though the current results of applying the LEEFT for water disinfection are exciting, tremendous research efforts are still needed. The state-of-art LEEFT electrodes can last for 15 days in continuous operation, which is probably already durable enough for some point-of-use (POU) applications. However, practical applications in larger scales desire much longer lifespan. Understanding the process of electrode erosion and developing more durable electrodes are still critical for the future implementation of the LEEFT. In terms of the engineering aspects of the LEEFT, designing better configuration for LEEFT devices is needed to allow higher flux, better transportation of cells to the area with enhanced electric field, and increased versatility for use in different scenarios.

In terms of the inactivation mechanisms, direct evidence to support irreversible electroporation causing cell death is still lacking. For example, direct observation of electroporated pores forming on the cell membrane subjected to the LEEFT is worth investigating. The visualization or measurement of the high electric field strength has not yet been achieved by experimental methods. Simulation results have shown that the high electric field is limited to small regions that are within a few $\mu \mathrm{m}$ away from the tips. Theoretically, microbes should be present in these regions to be inactivated by electroporation. Experimental results have shown that hydraulic, electrophoretic, and dielectrophoretic forces play important roles for transporting the microbes. However, more comprehensive experiments and modeling studies are still needed to quantify the contribution of these forces.

Before any practical application, the LEEFT should also be tested for treating more microbial species, including bacterial spores, disinfection-resistant bacteria, protozoa, and viruses. Moreover, systematic investigations on the impact of water quality parameters (e.g., $\mathrm{pH}$, temperature, turbidity, and ion strength) on LEEFT performance are required. The influence of the LEEFT on the microbial community structure should also be investigated.

Next-generation water disinfection methods should minimize the use of chemicals, the consumption of energy, and the impact on the environment. The LEEFT has great potential to transform current water disinfection strategies and systems. Potential advantages of the LEEFT include the following: i) high microbial inactivation efficiency; ii) broad-spectrum effectivity to all pathogens; iii) a fast treatment process; iv) low capital, operational, and maintenance cost; v) no impact on the physical and chemical properties of the treated water (i.e., neither generating DBPs nor releasing toxic metals nor increasing the corrosivity); vi) inactivation using electricity without any chemical consumption; vii) no over-treatment concerns; viii) facile operation and the possibility for automatic operation; ix) no secondary pollution in terms of odor, sound, or light; and x) a completely safe treatment process that poses no hazard to operators and nearby community. If these features are achieved, the LEEFT can potentially be applicable at all scales, from portable devices to household units and from distributed community-scale treatment clusters to centralized treatment plants. Some of the advantages mentioned above are especially attractive for small drinking water systems that may be very close to residential areas, have difficulties in chemical delivery and storage, or lack of knowledgeable operators. For some remote places without reliable grid power (e.g., islands, ships, and developing areas) or some emergency situations when the grid power is disrupted (e.g., earthquakes and hurricanes), the LEEFT can also be easily powered by batteries or renewable energy sources, such as wind, solar, and hydropower. Therefore, we believe the LEEFT will be a promising water disinfection technology that provides more accessible and reliable protection for public health.

Acknowledgements We acknowledge the financial support from the National Science Foundation via Grant CBET 1845354. J. Z. acknowledges the support from the NWRI/BioLargo, Inc. Fellowship. T.W. is grateful for the financial support provided by the China Scholarship Council.

Open Access This article is licensed under a Creative Commons Attribution 4.0 International License, which permits use, sharing, adaptation, distribution and reproduction in any medium or format, as long as you give appropriate credit to the original author(s) and the source, provide a link to the Creative Commons licence, and indicate if changes were made. The images or other third party material in this article are included in the article's Creative Commons licence, unless indicated otherwise in a credit line to the material. If material is not included in the article's Creative Commons licence and your intended use is not permitted by statutory regulation or exceeds the permitted use, you will need to obtain permission directly from the copyright holder. To view a copy of this licence, visit http://creativecommons.org/licenses/by/4.0/. 


\section{References}

Akhavan O, Ghaderi E (2010). Toxicity of graphene and graphene oxide nanowalls against bacteria. ACS Nano, 4(10): 5731-5736

Barba F J, Parniakov O, Pereira S A, Wiktor A, Grimi N, Boussetta N, Saraiva J A, Raso J, Martin-Belloso O, Witrowa-Rajchert D, Lebovka N, Vorobiev E (2015). Current applications and new opportunities for the use of pulsed electric fields in food science and industry. Food Research International, 77: 773-798

Centers for Disease Control and Prevention (1999). A Century of U.S. Water Chlorination and Treatment: One of the Ten Greatest Public Health Achievements of the 20th Century. MMWR. Morbidity and Mortality Weekly Report, 48(29): 621-629

Chang B Y, Park S M (2010). Electrochemical impedance spectroscopy. Annual Review of Analytical Chemistry (Palo Alto, Calif.), 3(1): 207-229

Chang Y, Reardon D J, Kwan P, Boyd G, Brant J, Rakness K L, Furukawa D (2008). Evaluation of dynamic energy consumption of advanced water and wastewater treatment technologies. AWWA Research Foundation \& California Energy Commission, Denver

Cho K, Qu Y, Kwon D, Zhang H, Cid C A, Aryanfar A, Hoffmann M R (2014). Effects of anodic potential and chloride ion on overall reactivity in electrochemical reactors designed for solar-powered wastewater treatment. Environmental Science \& Technology, 48(4): 2377-2384

Deborde M, von Gunten U (2008). Reactions of chlorine with inorganic and organic compounds during water treatment-Kinetics and mechanisms: A critical review. Water Research, 42(1-2): 13-51

Ding W, Zhou J, Cheng J, Wang Z, Guo H, Wu C, Xu S, Wu Z, Xie X, Wang Z L (2019). TriboPump: A low-cost, hand-powered water disinfection system. Advanced Energy Materials, 9(27): 1901320

Edd J F, Horowitz L, Davalos R V, Mir L M, Rubinsky B (2006). In vivo results of a new focal tissue ablation technique: irreversible electroporation. IEEE Transactions on Biomedical Engineering, 53 (7): $1409-1415$

Flemming C, Trevors J (1989). Copper toxicity and chemistry in the environment: A review. Water, Air, and Soil Pollution, 44(1-2): 143158

Gusbeth C, Frey W, Volkmann H, Schwartz T, Bluhm H (2009). Pulsed electric field treatment for bacteria reduction and its impact on hospital wastewater. Chemosphere, 75(2): 228-233

Haas C N, Aturaliye D (1999). Semi-quantitative characterization of electroporation-assisted disinfection processes for inactivation of Giardia and Cryptosporidium. Journal of Applied Microbiology, 86 (6): 899-905

Huo Z Y, Liu H, Wang W L, Wang Y H, Wu Y H, Xie X, Hu H Y (2019a). Low-voltage alternating current powered polydopamineprotected copper phosphide nanowire for electroporation-disinfection in water. Journal of Materials Chemistry. A, Materials for Energy and Sustainability, 7(13): 7347-7354

Huo Z Y, Liu H, Yu C, Wu Y H, Hu H Y, Xie X (2019b). Elevating the stability of nanowire electrodes by thin polydopamine coating for low-voltage electroporation-disinfection of pathogens in water. Chemical Engineering Journal, 369: 1005-1013

Huo Z Y, Luo Y, Xie X, Feng C, Jiang K, Wang J, Hu H Y (2017).
Carbon-nanotube sponges enabling highly efficient and reliable cell inactivation by low-voltage electroporation. Environmental Science. Nano, 4(10): 2010-2017

Huo Z Y, Xie X, Yu T, Lu Y, Feng C, Hu H Y (2016). Nanowiremodified three-dimensional electrode enabling low-voltage electroporation for water disinfection. Environmental Science \& Technology, 50(14): 7641-7649

Huo Z Y, Zhou J F, Wu Y, Wu Y H, Liu H, Liu N, Hu H Y, Xie X (2018). A Cu 3p nanowire enabling high-efficiency, reliable, and energy-efficient low-voltage electroporation-inactivation of pathogens in water. Journal of Materials Chemistry. A, Materials for Energy and Sustainability, 6(39): 18813-18820

Jiang C, Davalos R V, Bischof J C (2015). A review of basic to clinical studies of irreversible electroporation therapy. IEEE Transactions on Biomedical Engineering, 62(1): 4-20

Kotnik T,Bobanovic F, Miklavčič D (1997). Sensitivity of transmembrane voltage induced by applied electric fields - A theoretical analysis. Bioelectrochemistry (Amsterdam, Netherlands), 43(2): 285-291

Kotnik T, Frey W, Sack M, Haberl Meglič S, Peterka M, Miklavčič D (2015). Electroporation-based applications in biotechnology. Trends in Biotechnology, 33(8): 480-488

Kotnik T, Rems L, Tarek M, Miklavčič D (2019). Membrane electroporation and electropermeabilization: Mechanisms and models. Annual Review of Biophysics, 48(1): 63-91

Liu C, Xie X, Zhao W, Liu N, Maraccini P A, Sassoubre L M, Boehm A B, Cui Y (2013). Conducting nanosponge electroporation for affordable and high-efficiency disinfection of bacteria and viruses in water. Nano Letters, 13(9): 4288-4293

Liu C, Xie X, Zhao W, Yao J, Kong D, Boehm A B, Cui Y (2014). Static electricity powered copper oxide nanowire microbicidal electroporation for water disinfection. Nano Letters, 14(10): 5603-5608

Mizuno A, Inoue T, Yamaguchi S, Sakamoto K I, Saeki T, Matsumoto Y, Minamiyama K (1990). Inactivation of viruses using pulsed high electric field: IEEE, 713-719

Morris R D, Audet A M, Angelillo I F, Chalmers T C, Mosteller F (1992). Chlorination, chlorination by-products, and cancer: A metaanalysis. American Journal of Public Health, 82(7): 955-963

Pethig R, Markx G H (1997). Applications of dielectrophoresis in biotechnology. Trends in Biotechnology, 15(10): 426-432

Plewa M J, Wagner E D, Jazwierska P, Richardson S D, Chen P H, McKague A B (2004). Halonitromethane drinking water disinfection byproducts: chemical characterization and mammalian cell cytotoxicity and genotoxicity. Environmental Science \& Technology, 38(1): 62-68

Poudineh M, Mohamadi R M, Sage A, Mahmoudian L, Sargent E H, Kelley S O (2014). Three-dimensional, sharp-tipped electrodes concentrate applied fields to enable direct electrical release of intact biomarkers from cells. Lab on a Chip, 14(10): 1785-1790

Rojas-Chapana J A, Correa-Duarte M A, Ren Z, Kempa K, Giersig M (2004). Enhanced introduction of gold nanoparticles into vital Acidothiobacillus ferrooxidans by carbon nanotube-based microwave electroporation. Nano Letters, 4(5): 985-988

Saldaña G, Álvarez I, Condón S, Raso J (2014). Microbiological aspects related to the feasibility of PEF technology for food pasteurization. Critical Reviews in Food Science and Nutrition, 54(11): 1415-1426 
Saulis G (2010). Electroporation of cell membranes: The fundamental effects of pulsed electric fields in food processing. Food Engineering Reviews, 2(2): 52-73

Schoen D T, Schoen A P, Hu L, Kim H S, Heilshorn S C, Cui Y (2010). High speed water sterilization using one-dimensional nanostructures. Nano Letters, 10(9): 3628-3632

Sedlak D L, von Gunten U (2011). Chemistry. The chlorine dilemma. Science, 331(6013): 42-43

Shahini M, Yeow J T (2013). Cell electroporation by CNT-featured microfluidic chip. Lab on a Chip, 13(13): 2585-2590

Spilimbergo S, Dehghani F, Bertucco A, Foster N R (2003). Inactivation of bacteria and spores by pulse electric field and high pressure $\mathrm{CO}_{2}$ at low temperature. Biotechnology and Bioengineering, 82(1): 118-125

Stewart M P, Langer R, Jensen K F (2018). Intracellular delivery by membrane disruption: mechanisms, strategies, and concepts. Chemical Reviews, 118(16): 7409-7531

Tieleman D P, Leontiadou H, Mark A E, Marrink S J (2003). Simulation of pore formation in lipid bilayers by mechanical stress and electric fields. Journal of the American Chemical Society, 125(21): 63826383

USEPA (2009). National Primary Drinking Water Regulations
Vecitis C D, Schnoor M H, Rahaman M S, Schiffman J D, Elimelech M (2011). Electrochemical multiwalled carbon nanotube filter for viral and bacterial removal and inactivation. Environmental Science \& Technology, 45(8): 3672-3679

Wang T, Chen H, Yu C, Xie X (2019). Rapid determination of the electroporation threshold for bacteria inactivation using a lab-on-achip platform. Environment International, 132: 105040

Weaver J C, Chizmadzhev Y A (1996). Theory of electroporation: A review. Bioelectrochemistry and Bioenergetics, 41(2): 135-160

Westerhoff P, Yoon Y, Snyder S, Wert E (2005). Fate of endocrinedisruptor, pharmaceutical, and personal care product chemicals during simulated drinking water treatment processes. Environmental Science \& Technology, 39(17): 6649-6663

Zhou J, Wang T, Chen W, Lin B, Xie X (2019a). Emerging investigator series: Locally enhanced electric field treatment (LEEFT) with nanowire modified electrodes for water disinfection in pipes. Environmental Science: Nano, Advance Article,

Zhou J, Wang T, Xie X (2019b). Rationally designed tubular coaxialelectrode copper ionization cells (CECICs) harnessing non-uniform electric field for efficient water disinfection. Environment International, 128: $30-36$ 


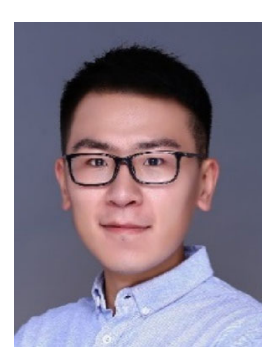

Jianfeng Zhou is currently a Ph.D. candidate in the School of Civil \& Environmental Engineering at Georgia Institute of Technology. Before that, he received his B.S. and M. S. degrees from Harbin Institute of Technology in 2015 and University of Washington in 2017, respectively. His research interests include environmental nanotechnology and its applications in water disinfection.

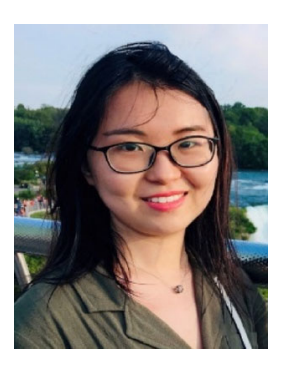

Ting Wang received her master's degree in environmental science from Peking University in 2017. Following this, she started her Ph.D. studentship, supervised by Dr. Xing Xie at Georgia Institute of Technology. Her research interests mainly focus on the mechanisms of using locally enhanced electric field treatment (LEEFT) for bacteria disinfection.

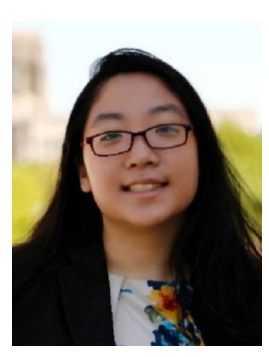

Cecilia Yu received her undergraduate degree from the University of Chicago in 2017 before applying for a Ph.D. in environmental engineering. She is currently studying under Dr. Xing Xie at the Georgia Institute of Technology. Her research interests include the development of novel nanomaterials for low voltage electroporation-based disinfection and the practical applications of LEEFT in drinking water treatment.

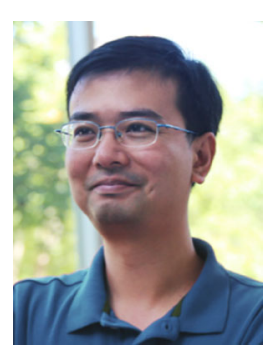

Dr. Xing Xie received his B.S. (2006) and M. S. (2008) degrees in Environmental Science \& Engineering from Tsinghua. He received his Ph.D. degree (2014) in Civil \& Environmental Engineering and his second M.S. degree (2012) in Materials Science \& Engineering from Stanford. Prior to joining Georgia Tech in 2017, he was a postdoc at Caltech. He has been applying environmental biotechnology and materials science to address challenges at the nexus of water and energy. Dr. Xie is a recipient of the US NSF CAREER award in 2019. 